\title{
Influence of match quality on men's volleyball performance at different competition levels
}

\author{
Antonio García-de-Alcaraz ${ }^{\mathrm{a}}$ (D) and Rui Marcelino ${ }^{\mathrm{b}, \mathrm{c}}$ (1) \\ aLFE Research Group. Faculty of Physical Activity and Sport Sciences-INEF, Technical University of Madrid, \\ Madrid, Spain; ${ }^{\text {b}}$ Research Center in Sports Sciences, Health Sciences and Human Development, CIDESD, \\ Portugal; ' CUniversity Institute of Maia, ISMAI, Maia, Portugal
}

\begin{abstract}
Performance in team sports is the result of a dynamic and interactive process between two opposing teams. The aim of this study was to examine the performance of volleyball players executing terminal actions (i.e. serve, attack, block and counter-attack) in terms of match quality. Three hundred and seven sets were selected randomly from U14s up to Olympic level and analysed according to type of match: balanced (strong vs. strong, and weak vs. weak teams) and unbalanced matches (strong vs. weak). The variables analysed were: competition category, frequency of use and coefficient of efficacy for each technical-tactical action, and way of execution in terms of match quality. A K-means cluster analysis was performed to divide teams into two groups according to quality (stronger or weaker teams). The change between the types of match was estimated by means of effect size at $90 \%$ confidence intervals. Few and small differences between balanced and unbalanced matches were found. Most changes were related to play style, and happened in balanced matches and in initial age categories. The findings may be useful for coaches, physical trainers and match analysts when evaluating team performance and designing plans according to competition demands and players' stages of development.
\end{abstract}

\section{ARTICLE HISTORY}

Received 24 March 2017

Accepted 26 June 2017

\section{KEYWORDS}

Team sports; age groups; performance analysis; situational variables; team quality

\section{Introduction}

Sport teams compare their performance systematically through official competitions (Nevill, Atkinson, \& Hughes, 2008). Performance is the result of an interactive process mediated by game rules, characteristics and coordination of players, and by the influence of the opposing team (Gréhaigne, Bouthier, \& David, 1997; McGarry, Anderson, Wallace, Hughes, \& Franks, 2002). This performance is unpredictable (Jäger \& Schöllhorn, 2007; Lames \& McGarry, 2007) and self-regulatory depending on environmental conditions besides the opponent's influence (Hristovski, Davids, \& Duarte, 2009). External and indirect conditions that may influence sport performance (match style or outcome) are frequently known as "situational variables". Some situational variables, such as quality of opposition (i.e. difference in play 
levels - usually final ranking - between opposing teams), match status or score line (i.e. difference in game final score), match location (i.e. place where the game is played at home or away), or game period (i.e. critical moments during a match), have been identified as potential influences of sport performance (Gómez, Lago-Peñas, \& Pollard, 2013).

Quality of opposition (QO) is based on "quality" and "type" of opponent team. "Quality" of team refers to a team's ranking position or its chances of winning, while "type" of team points at how a team performs (play style) rather than successful performance (O'Donoghue, 2009). Thus, QO may be measured in terms of either the distance between the ranked positions of teams (Lago-Penas, Gómez, Viaño, González-García, \& Fernández-Vilariño, 2013; Oliveira, Gómez, \& Sampaio, 2012; Ruano, Serna, Lupo, \& Sampaio, 2013) or by performance indicators such as matches won, points/goals scored, etc. (Gómez, Prieto, Pérez, \& Sampaio, 2013; Marcelino, Mesquita, \& Sampaio, 2011). When teams interact in a match, QO results in a particular type of match which may be defined as match quality. Hence, if the quality of both teams is similar, there will be a balanced match, while dissimilar qualities will lead to an unbalanced match.

Research has identified some performance differences between balanced and unbalanced matches in terms of: (a) physical efforts - more intensity in balanced matches in contrast to alternative intensities in unbalanced matches (Ruano et al., 2013); (b) technical-tactical performance indicators - an increase in game velocity and efficacy of scoring actions (attack and block) in balanced matches in volleyball (Marcelino et al., 2011), and an increase in space occupation in unbalanced matches in football (Castellano, Álvarez, Figueira, Coutinho, \& Sampaio, 2013); (c) game outcomes - the higher the quality differences between teams, the larger the difference in score (Lago-Penas et al., 2013; Moreno, Gómez, Lago, \& Sampaio, 2013); and (d) match quality, which minimises the impact of other situational variables the more balanced a match is, the stronger the influence of game location in basketball (Moreno et al., 2013), handball (Oliveira et al., 2012) and water polo (Ruano et al., 2013) and the stronger the score equality in volleyball (Marcelino et al., 2011).

Only three studies on quality of opposition in volleyball have been found (Marcelino, Mesquita, \& Sampaio, 2010, 2011; Marcelino, Sampaio, \& Mesquita, 2012). Despite their major contributions, these studies focus solely on top-level competitions and performance outcomes of scoring technical-tactical actions. Therefore, there is a lack of knowledge of initial age categories, when there is a complex interaction between changes in the rules (raise net height), maturity of players and training evolution (Burgess \& Naughton, 2010). At these age categories, players' performance is influenced more by maturity than by training process, and by how performance changes varies from one sport to another (Baxter-Jones, Helms, Maffulli, Baines-Preece, \& Preece, 1995). In volleyball, García-de-Alcaraz, Valadés, and Palao (in press) identified performance reference values for technical-tactical actions and physical efforts in initial age categories and in top-level competitions. However, these reference values were general for each competition category and did not show any possible influences of quality of opposition on playing styles and, therefore, on the specific technicaltactical performance displayed during the different type of matches.

Gaining some knowledge of these topics would be useful for coaches because they could identify competition demands in terms of match quality and be able to design a coherent and optimal training plan. Thus, the aim of this study was to examine how players execute and perform terminal actions (serve, attack, block and counter-attack) throughout various stages of development in men's volleyball in terms of match quality. 


\section{Method}

\subsection{Sample}

Three hundred and seven sets from 178 matches by 165 teams were randomly selected and analysed according to type of match (balanced or unbalanced - see procedures section for further details) in different age group categories. The selected sets came from the Spanish National Championships for U14, U16 and U19 categories (2008-2009 season), Spain's first division (men national category, 2008-2009 and 2009-2010 seasons) and the 2008 Olympic Games (men international category) (Table 1). The fifth set (tiebreak) was not included as it has a different structure (FIVB, 2013). The study was approved by the Bioethics Commission of the University of Murcia and complied with the ethical principles of the Declaration of Helsinki.

Table 1. Number of teams and sets observed in matches played in each age group category according to the type of match.

\begin{tabular}{lcccccc}
\hline & \multicolumn{3}{c}{ Balanced matches } & \multicolumn{3}{c}{ Unbalanced matches } \\
\cline { 2 - 7 } & Sets & Matches & Teams & Sets & Matches & Teams \\
\hline Under 14 (U14) & 55 & 30 & 21 & 16 & 13 & 12 \\
Under 16 (U16) & 32 & 23 & 20 & 30 & 21 & 21 \\
Under 19 (U19) & 36 & 18 & 19 & 29 & 20 & 20 \\
Men national & 38 & 17 & 18 & 25 & 11 & 11 \\
Men international & 33 & 12 & 12 & 13 & 13 & 11 \\
Total & 194 & 100 & 90 & 113 & 78 & 75 \\
\hline
\end{tabular}

\subsection{Design}

An observational design was implemented (Anguera, 2003). The included variables were: (a) category of competition: Under-14, Under-16, Under-19, men national and men international; (b) frequency of use of each technical-tactical action and way of execution: (b1) jump spin, jump float or standing serve; and (b2) first, second or third tempo execution (Costa et al., 2011) for attack (after reception), counter-attack (after dig) and block (faced to attack or counter-attack); and (c) coefficient of efficacy of each technical-tactical action according to way of execution. Five levels for categorising the serve were used: error (0), maximum opponent attack options (1), limited opponent attack options (2), no opponent attack options (3) and point (4). Four levels for categorising the attack, counter-attack and block were chosen: error (0), maximum or limited opponent counter-attack options (1), no opponent counter-attack options (3) and point (4) (García-de-Alcaraz, Ortega, \& Palao, $2015,2016 \mathrm{a}, 2016 \mathrm{~b})$. The maximum and limited opponent options were joined in a category (for attack, counter-attack and block) due to the lower frequency of maximum options in counter-attack (less than 5\%) for the opponent team after a spike, especially at top-level categories (Palao, Santos, \& Ureña, 2007). The coefficient efficacy of each terminal action and how it was executed was calculated by adding up the attempts made for each level multiplied by the level-value and divided by the total number of attempts (Coleman, 2002).

\subsection{Procedures}

Matches were recorded with digital video cameras located at the end of the court and at a height above that of the net, except for Olympic Games matches, where filming took place from the sides and the back of the court. This ensured a full view of the official court area 
was filmed. Actions were recorded by an observer using Data Volley 2007 software (Data Project Sport Software, Bologna, Italy). The observer had a degree in sport sciences, the highest volleyball coaching certification at Spanish national level, and over 10 years experience in coaching and performance analysis in volleyball. To ensure the quality of data coding and variables, a training process was undertaken before starting the study. In order to calculate reliability, Cohen's Kappa analysis was conducted. For an intra-reliability analysis, $20 \%$ of sets from each category of competition were randomly selected and observed. For an inter-observer reliability analysis, $25 \%$ of sets from the men national category were randomly selected and analysed by a second observer who was highly experienced in volleyball performance analysis and in the use of the observational software used in this study. Intra- and inter-reliability showed a good strength of agreement in all variables $(\kappa=.61$ and above) (Robinson \& O’Donoghue, 2007).

The data of the performed actions were collected with Data Volley 2007 software and displayed in spreadsheets. Data were merged into a single matrix in which contextual variables (category, team quality, type of match and set result) were included.

Following Marcelino et al. (2011), a K-means cluster analysis (Schwartz's Bayesian) was performed in order to divide teams into two groups according to quality - strong or weak. Differences in teams' quality led to two types of matches: (a) balanced matches (played by two teams of similar quality: strong vs. strong, or weak vs. weak), or (b) unbalanced matches (played by two teams of dissimilar quality). These data were analysed with the SPSS v.21.0. (Statistical Package for the Social Sciences, SPSS Inc). The differences between balanced and unbalanced matches were graphically represented with Prism 7.0. (GraphPad Software, Inc).

\subsection{Statistical analysis}

The amount of change in each variable between the two types of match was calculated by effect size (ES) at 90\% confidence intervals (CIs) using standardised differences in means (SDMs) and saved in spreadsheets files (Hopkins, 2007). The ES and CIs were used to contribute in a more informative way and for more practical significance. This approach gives consistent hands-on information about the amount and direction of change between groups (Cumming, 2012). Differences were calculated for the frequency of use and the coefficient of efficacy according to the category of competition for each action and way of execution. The magnitude threshold between balanced or unbalanced matches was set at $0-0.2$ trivial, $>0.2-0.6$ small, $>0.6-1.2$ moderate, $>1.2-2$ large and $>2$ very large. These magnitude thresholds were redefined in non-clinical qualitative probabilistic terms as $<0.5 \%$ unclear, $>0.5-5 \%$ very unlikely, $>5-25 \%$ unlikely, $>25-75 \%$ possible, $>75-95 \%$ likely, $>95-99.5 \%$ very likely and $>99.5 \%$ most likely (Hopkins, Marshall, Batterham, \& Hanin, 2009). The direction of change indicates that a positive effect refers to an unbalanced match while a negative effect points to a balance match.

\section{Results}

Table 2 shows the descriptive analysis and the magnitude-based differences (ES \pm CIs) between balanced and unbalanced matches in the variables that showed more than a trivial change $(\mathrm{ES}>0.20)$. The variables showed small differences, except for the $\mathrm{CoE}$ of the jump float serve at U14, the CoE of the first tempo block at U16 and the FoU of the first tempo counter-attack at men international category, which showed moderate differences. 
Table 2. Descriptive data for type of match, and effect size ( $90 \% \mathrm{Cls}$ ) and probably criteria related to the frequency of use and the coefficient of efficacy for each action and way of execution.

\begin{tabular}{|c|c|c|c|c|c|c|c|c|c|}
\hline & & & \multirow[b]{2}{*}{ Cat. } & \multicolumn{2}{|c|}{ Balanced } & \multicolumn{2}{|c|}{ Unbalanced } & \multicolumn{2}{|c|}{ Effect Size } \\
\hline & & & & $n$ & Mean \pm SD & $n$ & Mean \pm SD & $\mathrm{ES} \pm \mathrm{Cls}$ & Crit. \\
\hline \multirow[t]{10}{*}{ Serve } & FoU & Total & U14 & 110 & $21.58 \pm 4.67$ & 32 & $20.25 \pm 5.27$ & $-0.23 \pm 0.34$ & I- \\
\hline & & & $\mathrm{Ml}$ & 66 & $23.47 \pm 2.94$ & 52 & $22.54 \pm 3.36$ & $-0.29 \pm 0.31$ & 1- \\
\hline & & Floating & U16 & 64 & $38.84 \pm 23.70$ & 60 & $44.29 \pm 30.81$ & $0.37 \pm 0.32$ & $a+$ \\
\hline & & Jump & U19 & 72 & $46.33 \pm 21.60$ & 58 & $54.67 \pm 24.52$ & $0.38 \pm 0.29$ & $a+$ \\
\hline & & Standing & U14 & 110 & $76.28 \pm 23.25$ & 32 & $79.56 \pm 14.91$ & $0.29 \pm 0.26$ & /+ \\
\hline & & & U19 & 72 & $41.30 \pm 25.47$ & 58 & $37.08 \pm 24.42$ & $-0.33 \pm 0.30$ & $a-$ \\
\hline & $\mathrm{CoE}$ & Total & U14 & 110 & $2.00 \pm 0.35$ & 32 & $1.86 \pm 0.41$ & $-0.38 \pm 0.36$ & $a-$ \\
\hline & & Power & U16 & 36 & $1.46 \pm 0.76$ & 27 & $1.38 \pm 0.93$ & $-0.27 \pm 0.46$ & I- \\
\hline & & Jump & $\mathrm{MI}$ & 66 & $1.19 \pm 0.29$ & 52 & $1.25 \pm 0.27$ & $0.24 \pm 0.30$ & /+ \\
\hline & & $\begin{array}{c}\text { Floating } \\
\text { Jump }\end{array}$ & U14 & 79 & $2.16 \pm 0.67$ & 23 & $1.57 \pm 0.64$ & $-0.93 \pm 0.43$ & $c-$ \\
\hline \multirow[t]{11}{*}{ Attack } & FoU & Total & U14 & 110 & $11.40 \pm 3.96$ & 32 & $10.16 \pm 3.58$ & $-0.24 \pm 0.31$ & $1-$ \\
\hline & & & U16 & 64 & $14.80 \pm 3.46$ & 60 & $13.35 \pm 3.46$ & $-0.41 \pm 0.30$ & $a-$ \\
\hline & & & $\mathrm{MI}$ & 66 & $17.67 \pm 3.06$ & 52 & $16.52 \pm 3.62$ & $-0.36 \pm 0.31$ & $a-$ \\
\hline & & $1 \mathrm{st} t$. & U16 & 64 & $9.87 \pm 12.21$ & 60 & $7.63 \pm 10.34$ & $-0.22 \pm 0.41$ & I- \\
\hline & & & MN & 76 & $29.27 \pm 11.64$ & 50 & $33.30 \pm 11.52$ & $0.28 \pm 0.30$ & /+ \\
\hline & & $2 n d t$. & MN & 76 & $57.27 \pm 13.75$ & 50 & $51.06 \pm 11.77$ & $-0.42 \pm 0.30$ & $a-$ \\
\hline & & $3 r d t$. & U16 & 64 & $86.38 \pm 16.46$ & 60 & $90.94 \pm 11.52$ & $0.34 \pm 0.29$ & $a+$ \\
\hline & & & MN & 76 & $13.46 \pm 10.70$ & 50 & $15.65 \pm 8.26$ & $0.27 \pm 0.31$ & $1+$ \\
\hline & $\mathrm{CoE}$ & Total & U16 & 64 & $2.29 \pm 0.43$ & 60 & $2.15 \pm 0.49$ & $-0.34 \pm 0.30$ & $a-$ \\
\hline & & $1 \mathrm{st} \mathrm{t}$. & MN & 75 & $2.76 \pm 0.72$ & 50 & $2.85 \pm 0.73$ & $0.25 \pm 0.29$ & /+ \\
\hline & & $3 r d t$. & U16 & 64 & $2.28 \pm 0.53$ & 60 & $2.11 \pm 0.47$ & $-0.31 \pm 0.30$ & $1-$ \\
\hline \multirow[t]{11}{*}{ Block } & FoU & Total & U16 & 64 & $10.47 \pm 4.12$ & 60 & $9.00 \pm 4.11$ & $-0.39 \pm 0.30$ & $a-$ \\
\hline & & & $\mathrm{MI}$ & 66 & $13.32 \pm 3.86$ & 52 & $12.25 \pm 4.19$ & $-0.30 \pm 0.31$ & $1-$ \\
\hline & & $1 \mathrm{st} t$. & MI & 66 & $14.96 \pm 9.88$ & 52 & $17.96 \pm 11.40$ & $0.33 \pm 0.33$ & /+ \\
\hline & & $2 n d t$. & MI & 66 & $53.18 \pm 13.29$ & 52 & $57.21 \pm 15.27$ & $0.24 \pm 0.30$ & $1+$ \\
\hline & & $3 \mathrm{rdt}$. & U16 & 64 & $89.18 \pm 15.77$ & 60 & $94.07 \pm 9.52$ & $0.39 \pm 0.29$ & $a+$ \\
\hline & & & MI & 66 & $31.85 \pm 13.04$ & 52 & $24.84 \pm 13.37$ & $-0.57 \pm 0.31$ & $b-$ \\
\hline & $\mathrm{CoE}$ & Total & U19 & 72 & $1.58 \pm 0.49$ & 58 & $1.45 \pm 0.50$ & $-0.29 \pm 0.30$ & I- \\
\hline & & $1 \mathrm{st} \mathrm{t}$. & U16 & 26 & $1.69 \pm 1.28$ & 20 & $2.24 \pm 1.65$ & $0.88 \pm 0.53$ & $b+$ \\
\hline & & & U19 & 57 & $1.99 \pm 1.19$ & 45 & $1.54 \pm 1.17$ & $-0.24 \pm 0.35$ & $1-$ \\
\hline & & $3 r d t$. & U19 & 71 & $1.51 \pm 0.65$ & 58 & $1.41 \pm 0.57$ & $-0.21 \pm 0.30$ & I- \\
\hline & & & MN & 75 & $1.88 \pm 0.95$ & 49 & $1.71 \pm 0.89$ & $-0.24 \pm 0.31$ & 1- \\
\hline \multirow{10}{*}{$\begin{array}{c}\text { Counter- } \\
\text { attack }\end{array}$} & FoU & Total & U14 & 110 & $15.37 \pm 6.44$ & 32 & $12.47 \pm 6.15$ & $-0.46 \pm 0.36$ & $a-$ \\
\hline & & $1 \mathrm{st} t$. & U16 & 64 & $6.39 \pm 9.07$ & 60 & $5.05 \pm 6.21$ & $-0.31 \pm 0.43$ & I- \\
\hline & & & $\mathrm{Ml}$ & 66 & $9.12 \pm 8.41$ & 52 & $8.51 \pm 10.89$ & $0.83 \pm 0.42$ & $b+$ \\
\hline & & $2 n d t$. & $\mathrm{Ml}$ & 66 & $38.04 \pm 15.80$ & 52 & $45.16 \pm 18.40$ & $0.56 \pm 0.31$ & $b+$ \\
\hline & & $3 r d t$. & U16 & 64 & $90.39 \pm 12.59$ & 60 & $93.81 \pm 7.14$ & $0.35 \pm 0.29$ & $a+$ \\
\hline & & & $\mathrm{Ml}$ & 66 & $52.84 \pm 16.06$ & 52 & $46.33 \pm 17.74$ & $-0.52 \pm 0.31$ & $b-$ \\
\hline & $\mathrm{CoE}$ & $1 \mathrm{st} \mathrm{t}$. & U19 & 52 & $1.97 \pm 1.22$ & 50 & $2.45 \pm 1.13$ & $0.31 \pm 0.34$ & /+ \\
\hline & & & MN & 43 & $2.93 \pm 1.36$ & 35 & $2.79 \pm 1.31$ & $-0.34 \pm 0.39$ & $1-$ \\
\hline & & & MI & 44 & $2.72 \pm 1.55$ & 23 & $2.09 \pm 1.45$ & $-0.43 \pm 0.46$ & $a-$ \\
\hline & & $2 n d t$. & MI & 64 & $2.62 \pm 1.02$ & 49 & $2.41 \pm 0.93$ & $-0.21 \pm 0.31$ & $1-$ \\
\hline
\end{tabular}

Notes: Cat.: age group category; ES: effect size; Cls: confidence intervals; Crit.: criteria of ES classification (probabilistic change); FoU: frequency of use; CoE: coefficient of efficacy; 1st t.: first tempo; 2nd t.: second tempo; 3rd t.: third tempo; U14: under 14; U16: under 16; U19: under 19; MN: men national; MI: men international; /: less than 75\%; a: likely (75-95\%); b: very likely (95-99.5\%); c: most likely (>99.5\%); "-": negative change (to a balanced match); " + : positive change (to an unbalanced match).

Figure 1 shows the comparison between types of match (balanced and unbalanced matches - BM and UM) in terms of magnitude-based differences ( $E S \pm C I s)$ according to frequency of use (FoU) and coefficient of efficacy (CoE) for each action or way of execution in each category of competition. The variables with fewer than 20 cases $(n<20)$ were neglected in this analysis. The variables that showed at least a likely change $(>75 \%)$ are marked in bold. The majority of changes were found in the variables related to the FoU, in the balanced matches and at initial age categories. 

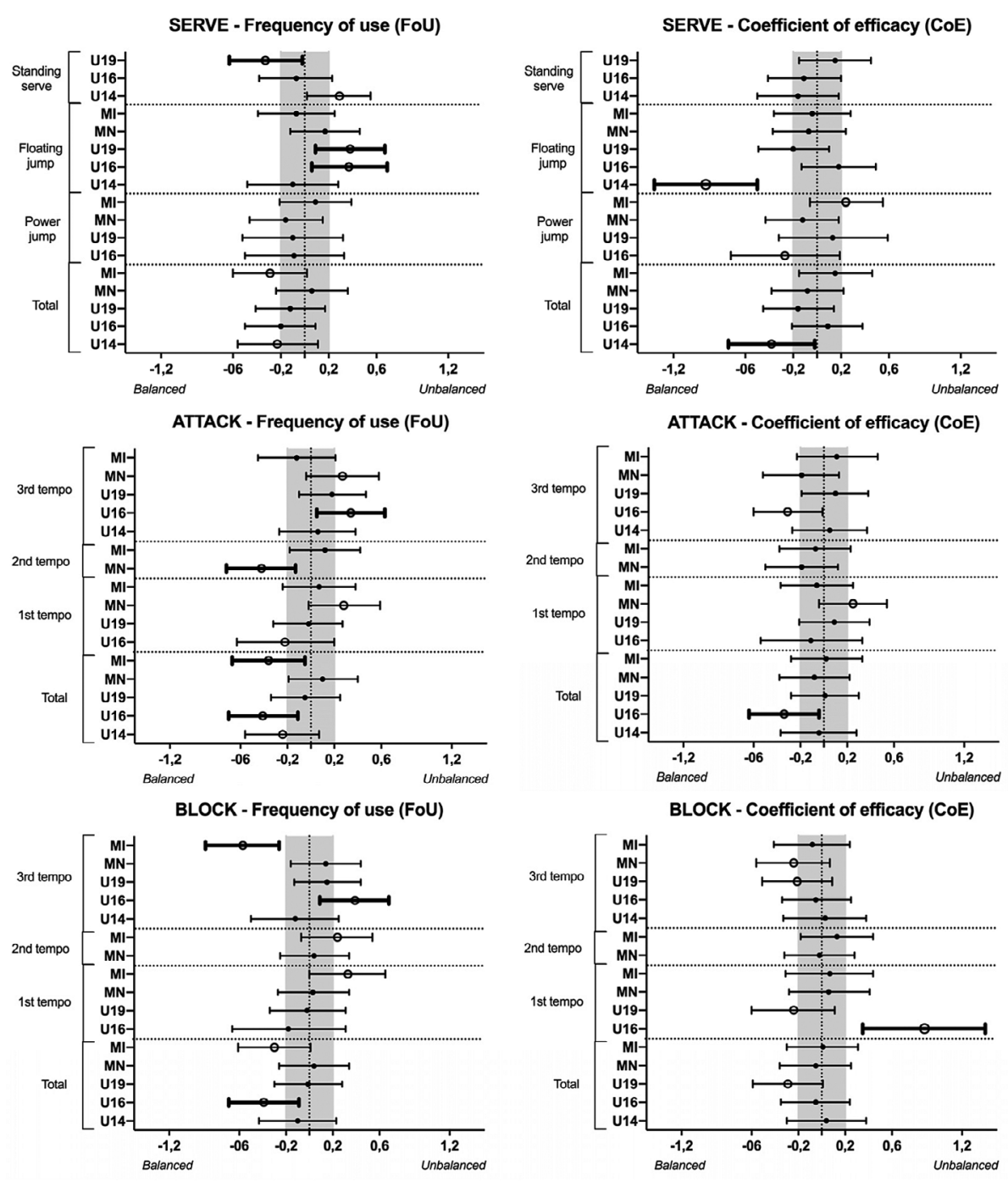

COUNTER-ATTACK - Frequency of use (FoU)
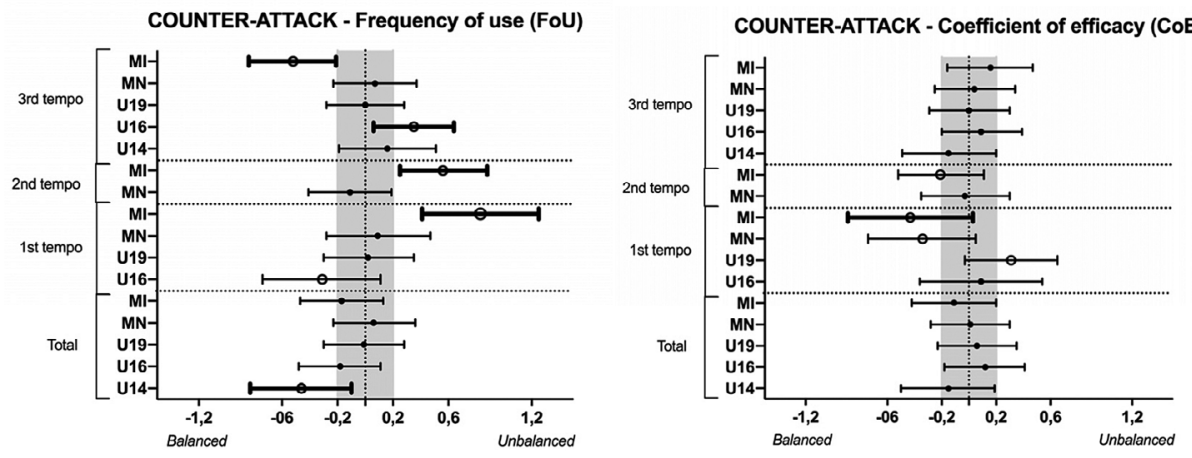

Figure 1. $\mathrm{ES} \pm \mathrm{Cls}(90 \%)$ related to the frequency of use and the coefficient of efficacy according to the category of competition for each action and way of execution.

Note: U14: under 14; U16: under 16; U19: under 19; MN: men national; MI: men international. 


\section{Discussion}

This study aimed to analyse the performance (frequency of use and coefficient of efficacy) of terminal actions (serve, attack, block and counter-attack) and the way actions are executed throughout various players' stages of development in men's volleyball in terms of quality of opposition. Few differences between balanced and unbalanced matches were found in the variables analysed (less than 35\%), and most of them were small (more than 90\%). However, most differences were related to play style (FoU), showed higher performance values in balanced matches $(\mathrm{BM})$ and occurred at initial age categories. Therefore, the quality of opposition (QO) has a relative influence on performance, at behavioural and outcome level, in different volleyball age-groups competitions.

According to players' stages of development, most differences in performance were found at initial age categories (from U14 to U19), and may be related to inconsistencies in players' performance (García-de-Alcaraz et al., in press), which may be associated with the maturity process and the development of anthropometric and physical characteristics (Nikolaidis et al., 2015). In contrast, the greater the proficiency in top-level competitions, the stronger the consistency in players' performance, aside from the influences of quality of opposition. From a developmental performance point of view, the variables that showed performance differences between balanced and unbalanced matches at initial age categories are rarely maintained in top-level competitions. These results highlight a lack of tendency between initial age groups and higher categories in terms of QO.

According to the total actions analysed (bottom part of each graph on the left side), a tendency was observed regarding the FoU: balanced matches have more actions in all categories, except for the men national category. Although the attack in U16 and men international categories, the block in U16 category and the counter-attack in U14 category show a likely change towards balanced matches, these results may be associated with more rallies played and/or a longer duration of each rally because of equality between teams. These results may be useful to trainers when training their athletes so that can they effectively handle increases in physical efforts (jumps and hits) or game situations under pressure as a result of particular competition demands when competing against teams of the same qualities. The differences between the men national category and the other categories may be due to some competition formula. Men national category was played in a round league system over the year, while the other categories where played at specific times of the year.

In serve, a higher $\mathrm{CoE}$ in BM was found in the U14 category (total serve and jump float serve) and in the U16 category (jump spin serve). The effectiveness of the jump serves may be related to the novelty of this kind of serves, and little training and experience in the reception performance by players at these age categories. In top-level competitions, only the jump spin serve shows a higher CoE in UM. These results highlight the disparate qualities between teams and may suggest that the stronger teams/players' serve outperform the opponent teams/players' reception. Other research studies have shown that the jump spin serve is the most frequently used option (Palao, Manzanares, \& Ortega, 2009) and increases the chances of winning a match (Peña, Rodríguez-Guerra, Buscà, \& Serra, 2013).

As to the FoU of the serve, higher frequencies of the jump float serve in UM in the U16 and U19 categories, and higher frequencies of the standing serve in BM in U19 category were found. The use of the jump float serve in UM shows that teams tend to take more risks in matches with dissimilar quality (we are unable to know which team, the stronger 
or the weaker, takes these risks), and fewer risks in matches with similar quality between teams (standing serve execution in higher BM). These results contradict those of Marcelino et al. (2011), who found more risks in balanced matches, especially with balanced scores. However, the competitions categories analysed could help to explain the incongruence of results between studies. Thus, teams taking more risks in balanced situations belonged to top-level competitions and were highly experienced, while in this study the teams that took fewer risks belonged to initial age categories. The last small difference revealed a higher frequency of standing serve in UM in U14, which is contrary to the arguments mentioned above but supports the prevalence of this type of serve at initial age categories (García-deAlcaraz et al., 2016a).

In attack, this study shows a higher FoU of first and third tempo attack in UM in the men national category. According to these results, an increase in first tempo attack in UM could be associated with the higher quality of the stronger teams to perform a good reception, while an increase in third tempo attack could be linked with the difficulty experienced by the weaker team to intercept the serve and launch a fast attack. This idea is coherent with that in the study of Papadimitriou, Pashali, Sermaki, Mellas, and Papas (2004), who showed the relationship between the reception performance and the attack tempo, however, this relationship had not been found in initial age categories (Costa et al., 2011). Also, results showed a higher CoE in first tempo attacks in UM in the men national category, probably associated with the reduction in time of attack at this competition level (Bergeles \& Nikolaidou, 2011) and the difficulty experienced by the defending team to develop a good defensive system (García-de-Alcaraz et al., 2016b). Surprisingly, a higher CoE of third tempo attack in BM was found in the U16 category. This result could be related to a shortage of this action in BM because of a higher use in UM in this category. The higher FoU of first tempo attack in BM in the U16 category may point at the development of attack systems (coordination reception-set-attack) and the need to perform them in balanced situations where teams must adopt exceptional strategies. Finally, the higher FoU of second tempo attack in BM in the men national category reinforce the idea of an increase in the speed of game when progressing to higher categories (García-de-Alcaraz et al., 2015, in press). To summarise, in this "speed" progression, the first attack tempo occurs sooner than the second.

Regarding the block in the men international category, a higher FoU of first and second tempo in UM, and a higher FoU of third tempo in BM were found. These results may suggest: (a) a decrease in speed of game which may increase the time available and the number of players who perform the block (Afonso, Mesquita, \& Palao, 2005), (b) an increase in the anthropometric and physical development in higher categories (Nikolaidis et al., 2015), (c) greater expertise and better technical level which promote a cohesive block at top levels (Araújo, Castro, Marcelino, \& Mesquita, 2010), and (d) better ability of players to spike against the block, so taking more risks in balanced situations. Therefore, block contacts depend not only on the quality of blockers but also on the performance of attack players. Thus, the higher FoU of third tempo in UM in the U16 category comes from an increase in the FoU of attacks and counter-attacks in this type of matches.

As to the CoE of the block, higher values were found in BM (first tempo in U19 and third tempo in U19 and men national categories) except for the U16 category, in which the greatest effectiveness was found in UM. These differences could be related to the variables explained above, especially in the block action, in which performance depends on previous actions (attack or counter-attack). 
Concerning the counter-attack in the men international category, there was a higher FoU of first and second tempo in UM, and a higher FoU of third tempo in BM. These findings support the idea of superiority of stronger teams to counter-attack as fast as possible when playing against weaker teams (UM), and a difficulty to do so when playing against teams of the same quality (BM). In contrast, a higher FoU of third tempo counter-attack in UM and of first tempo counter-attack in BM were found in the U16 category. These differences reveal the variances in players' development and teams' defensive systems across categories. In top-level competitions (men national and international categories), the fastest counter-attacks (first and second tempo showed a higher performance (CoE) in BM while in U19 the first tempo counter-attacks showed a higher performance only in UM. An explanation for these results is complicated because the counter-attack actions occur in a more "unstable" game phase in terms of the defence of the opponent's attack or counter-attack, and the capability of building the counter-attack. Thus, multiple variables may influence counter-attack performance (e.g. spike condition of the opponent team, block structure, rotation and position of the setter, etc.).

These results confirm the influence of QO on teams' performance in volleyball. Differences in performance in volleyball according to the QO have also been reported, but always in top-level volleyball competitions (Marcelino et al., 2010, 2011, 2012). Any comparison of the results of previous studies with those of the present research must be made carefully. On the one hand, the present study distinguishes between attack and counter-attack actions that occur under different game conditions (attack and defence phase, respectively). This difference has only been taken into account by Marcelino et al. (2011). On the other hand, the present study joins together teams with similar performance in a particular type of match (balanced matches), including strong vs. strong and weak vs. weak teams in the same category. In contrast, Marcelino et al. $(2011,2012)$ analyse two types of balanced matches, classifying confrontations as being between stronger or weaker teams. Despite these differences, all previous studies established team's performance level according to the matches, sets and points scored by any team. Furthermore, the present study deepens our understanding of play style (way of execution) in addition to the typically reported outcome information.

Generally speaking, interactions between QO and other situational variables such as match status (Drikos \& Vagenas, 2011; Marcelino et al., 2011) and game period (Marcelino et al., 2012) add more detailed information about this phenomenon, yet these variables were not included in this study. The influence of QO and other situational variables has been widely reported in other team sports (e.g. Lago-Penas et al., 2013; Oliveira et al., 2012; Ruano et al., 2013) and refer to top-level competitions. The present research study aims to shed light on the influence of $\mathrm{QO}$ on performance with a cross-sectional view that involves initial age categories.

In conclusion, the $\mathrm{QO}$ has a relative influence on performance but this influence varies in terms of age. Most changes occur at initial age categories and may be due to the ability of some players to alter the performance level of their team (inconsistency of performance), while at top-level training, expertise and technical-tactical adaptations are needed to improve a team's performance (consistency of performance). Hence, future studies should focus on the analysis of the interactive effects between $\mathrm{QO}$ and other situational variables (e.g. match status, game period or match location), maturity stages, other performance factors (e.g. anthropometrics, physical, psychological), role of play, etc. The results of this study provide new insights into training and research, especially with a long-term view, 
and may be useful to coaches, physical trainers and match analysts in order for assessing performance and training their teams bearing in mind competition demands and stages of development of players.

\section{Disclosure statement}

No potential conflict of interest was reported by the authors.

\section{ORCID}

Antonio García-de-Alcaraz (iD) http://orcid.org/0000-0001-8210-4118

Rui Marcelino (D) http://orcid.org/0000-0001-8717-3243

\section{References}

Afonso, J., Mesquita, I., \& Palao, J. M. (2005). Relationship between the tempo and zone of spike and the number of blockers against the hitters. International Journal of Volleyball Research, 8, 19-23.

Anguera, M. T. (2003). Observational methods (general). In R. Fernández-Ballesteros (Ed.), Encyclopedia of psychological assessment (pp. 632-637). London: Sage.

Araújo, R., Castro, J., Marcelino, R., \& Mesquita, I. R. (2010). Relationship between the opponent block and the hitter in elite male volleyball. Journal of Quantitative Analysis in Sports, 6(4), 1-10.

Baxter-Jones, A. D. G., Helms, P., Maffulli, N., Baines-Preece, J. C., \& Preece, M. (1995). Growth and development of male gymnasts, swimmers, soccer and tennis players: A longitudinal study. Annals of Human Biology, 22, 381-394.

Bergeles, N., \& Nikolaidou, M. E. (2011). Setter's performance and attack tempo as determinants of attack efficacy in Olympic-level male volleyball teams. International Journal of Performance Analysis in Sport, 11, 535-544.

Burgess, D. J., \& Naughton, G. A. (2010). Talent development in adolescent team sports: A review. International Journal of Sports Physiology and Performance, 5, 103-116.

Castellano, J., Álvarez, D., Figueira, B., Coutinho, D., \& Sampaio, J. (2013). Identifying the effects from the quality of opposition in a football team positioning strategy. International Journal of Performance Analysis in Sport, 13, 822-832.

Coleman, J. E. (2002). Scouting opponents and evaluating team performance. In D. Shondell, \& C. Reynaud (Eds.), The volleyball coaching bible (pp. 321-346). Champaign, IL: Human Kinetics.

Costa, G. C., Caetano, R., Ferreira, N. N., Junquira, G., Afonso, J., Costa, R. D., \& Mesquita, I. (2011). Determinants of attack tactics in youth male elite volleyball. International Journal of Performance Analysis in Sport, 11, 96-104.

Cumming, G. (2012). Understanding the new statistics. New York, NY: Routledge.

Drikos, S., \& Vagenas, G. (2011). Multivariate assessment of selected performance indicators in relation to the type and result of a typical set in men's elite volleyball. International Journal of Performance Analysis in Sport, 11, 85-95.

FIVB. (2013). Official volleyball rules. Retrieved from www.rfevb.com

García-de-Alcaraz, A., Ortega, E., \& Palao, J. M. (2015). Effect of age group on male volleyball players' technical-tactical performance profile for the spike. International Journal of Performance Analysis in Sport, 15, 668-686.

García-de-Alcaraz, A., Ortega, E., \& Palao, J. M. (2016a). Effect of age group on technical-tactical performance profile of the serve in men's volleyball. Perceptual and Motor Skills, 123, 508-525.

García-de-Alcaraz, A., Ortega, E., \& Palao, J. M. (2016b). Technical-tactical performance profile of the block and dig according to competition category in men's volleyball. Motriz, 22, 102-109.

García-de-Alcaraz, A., Valadés, D, \& Palao, J. M. (in press). Evolution of game’s demands from young to elite players in men's volleyball. International Journal of Sport Physiology and Performance. doi:10.1123/ijspp.2016-0027 
Gómez, M. A., Lago-Peñas, C., \& Pollard, R. (2013). Situational variables. In T. McGarry, P. O’Donoghue, \& J. Sampaio (Eds.), Routledge handbook of sports performance analysis (pp. 259-269). London: Routledge, Taylor \& Francis.

Gómez, M. A., Prieto, M., Pérez, J., \& Sampaio, J. (2013). Ball possession effectiveness in men's elite floorball according to quality of opposition and game period. Journal of Human Kinetics, 38, 227-237.

Gréhaigne, J. F., Bouthier, D., \& David, B. (1997). Dynamic-system analysis of opponent relationships in collective actions in soccer. Journal of Sports Sciences, 15, 137-149.

Hristovski, R., Davids, K. W., \& Duarte, A. (2009). Information for regulating action in sport: Metastability and emergence of tactical solutions under ecological constraints. In D. Araujo, H. Ripoll, \& M, Raab (Eds), Perspectives on cognition and action in sport (pp. 43-57). New York, NY: Nova Science.

Hopkins, W. G. (2007). A spreadsheet to compare means of two groups. Sportscience, 11, 22-24.

Hopkins, W. G., Marshall, S. W., Batterham, A. M., \& Hanin, J. (2009). Progressive statistics for studies in sports medicine and exercise science. Medicine and Science in Sports and Exercise, 41, 3-13.

Jäger, J. M., \& Schöllhorn, W. I. (2007). Situation-orientated recognition of tactical patterns in volleyball. Journal of Sports Sciences, 25, 1345-1353.

Lames, M., \& McGarry, T. (2007). On the search for reliable performance indicators in game sports. International Journal of Performance Analysis in Sport, 7, 62-79.

Lago-Penas, C., Gómez, M. A., Viaño, J., González-García, I., \& Fernández-Vilariño, M. A. (2013). Home advantage in elite handball: The impact of the quality of opposition on team performance. International Journal of Performance Analysis in Sport, 13, 724-733.

Marcelino, R., Mesquita, I., \& Sampaio, J. (2010). Efficacy of the volleyball game actions related to the quality of opposition. The Open Sports Sciences Journal, 3, 34-35.

Marcelino, R., Mesquita, I., \& Sampaio, J. (2011). Effects of quality of opposition and match status on technical and tactical performances in elite volleyball. Journal of Sports Sciences, 29, 733-741.

Marcelino, R., Sampaio, J., \& Mesquita, I. (2012). Attack and serve performances according to the match period and quality of opposition in elite volleyball matches. Journal of Strength and Conditioning Research, 26, 3385-3391.

McGarry, T., Anderson, D. I., Wallace, S. A., Hughes, M. K., \& Franks, I. M. (2002). Sport competition as a dynamical self-organizing system. Journal of Sports Sciences, 20, 771-781.

Moreno, E., Gómez, M. A., Lago, C., \& Sampaio, J. (2013). Effects of starting quarter score, game location, and quality of opposition in quarter score in elite women's basketball. Kinesiology, 45, 48-54.

Nevill, A., Atkinson, G., \& Hughes, M. (2008). Twenty-five years of sport performance research in the Journal of Sports Sciences. Journal of Sports Sciences, 26, 413-426.

Nikolaidis, P. T., Afonso, J., Buśko, K., Ingebrigtsen, J., Chtourou, H., \& Martin, J. J. (2015). Positional differences of physical traits and physiological characteristics in female volleyball players - The role of age. Kinesiology, 47, 75-81.

O'Donoghue, P. (2009). Interacting performances theory. International Journal of Performance Analysis in Sport, 9, 26-46.

Oliveira, T., Gómez, M., \& Sampaio, J. (2012). Effects of game location, period, and quality of opposition in elite handball performances. Perceptual and Motor Skills, 114, 783-794.

Palao, J. M., Manzanares, P., \& Ortega, E. (2009). Techniques used and efficacy of volleyball skills in relation to gender. International Journal of Performance Analysis in Sport, 9, 281-293.

Palao, J. M., Santos, J. A., \& Ureña, A. (2007). Effect of the manner of spike execution on spike performance in volleyball. International Journal of Performance Analysis in Sport, 7, 126-138.

Papadimitriou, K., Pashali, E., Sermaki, I., Mellas, S., \& Papas, M. (2004). The effect of the opponents' serve on the offensive actions of Greek setters in volleyball games. International Journal of Performance Analysis in Sport, 4, 23-33.

Peña, J., Rodríguez-Guerra, J., Buscà, B., \& Serra, N. (2013). Which skills and factors better predict winning and losing in high-level men's volleyball? Journal of Strength and Conditioning Research, 27, 2487-2493. 
Robinson, G., \& O’Donoghue, P. (2007). A weighted kappa statistic for reliability testingin performance analysis of sports. International Journal of Performance Analysis of Sport, 7, 12-19.

Ruano, M. A., Serna, A. D., Lupo, C., \& Sampaio, J. (2013). Effects of game location, quality of opposition, and starting quarter score in the outcome of elite water polo quarters. Journal of Strength and Conditioning Research, 30, 1014-1020. 